\title{
Noradrenergic Depletion Potentiates $\beta$-Amyloid-Induced Cortical Inflammation: Implications for Alzheimer's Disease
}

\author{
Michael T. Heneka, ${ }^{1}$ Elena Galea, ${ }^{2}$ Vitaliy Gavriluyk, ${ }^{2}$ Lucia Dumitrescu-Ozimek, ${ }^{1}$ JoAnna Daeschner, ${ }^{3}$ \\ M. Kerry O'Banion, ${ }^{3}$ Guy Weinberg, ${ }^{2}$ Thomas Klockgether, ${ }^{1}$ and Douglas L. Feinstein ${ }^{2}$ \\ ${ }^{1}$ Department of Neurology, University of Bonn, Germany 53127, '2Department of Anesthesiology, University of Illinois, Chicago, Illinois \\ 60612, and ${ }^{3}$ Department of Neurobiology and Anatomy, University of Rochester Medical Center, Rochester, New York 14642
}

\begin{abstract}
Degeneration of locus ceruleus (LC) neurons and reduced levels of norepinephrine (NE) in LC projection areas are well known features of Alzheimer's disease (AD); however, the consequences of those losses are not clear. Because inflammatory mediators contribute to AD pathogenesis and because NE can suppress inflammatory gene expression, we tested whether LC loss influenced the brain inflammatory gene expression elicited by amyloid $\beta(A \beta)$. Adult rats were injected with the selective neurotoxin $N$-(2-chloroethyl)- $N$-ethyl-2 bromobenzylamine (DSP4) to induce LC death and subsequently injected in the cortex with $A \beta$ (aggregated 1-42 peptide). DSP4 treatment potentiated the $A \beta$-dependent induction of inflammatory nitric oxide synthase (iNOS), interleukin (IL)- $1 \beta$, and IL- 6 expression compared with control animals. In contrast, the induction of cyclooxygenase-2 expression was not modified by DSP4 treat-
\end{abstract}

The locus ceruleus (LC) is the main subcortical site of norepinephrine (NE) synthesis and its precursor enzymes. Noradrenergic axons arising from LC neurons project to several cortical areas, including the hippocampus, entorhinal cortex, and frontal cortex, where their axon terminals are in close contact with neurons, astrocytes, and brain microvessels (Kalaria et al., 1989a; Paspalas and Papadopoulos, 1998). The LC-generated NE plays an important role in selective attention, general arousal, and stress reactions in response to challenging environmental situations (Foote et al., 1983; Levine et al., 1990), whereas experimentally induced loss of LC neurons has been implicated in learning and behavior deficits (Anlezark et al., 1973; Mason and Iversen, 1975; Harro et al., 1999). Loss of LC neurons, degeneration of noradrenergic projections, and a decrease in cortical NE levels are well described features of various neurodegenerative diseases, including Alzheimer's disease (AD) and Parkinson's disease. In addition, decreased LC neuronal counts are significantly correlated with the numbers of amyloid $\beta(\mathrm{A} \beta)$ plaques, neurofibrillary tangles, and the severity of dementia in AD (Bondareff et al., 1987). However, despite many experimental and neuropathological descriptions, the significance and role of LC cell death for neurodegenerative disease remains unclear.

\footnotetext{
Received Nov. 26, 2001; revised Jan. 3, 2002; accepted Jan. 7, 2002.

This study was supported in part by grants from the Deutsche Forschungsgemeinschaft (SFB 400, A8) to M.T.H. and T.K., a Gerok grant from Bonfor to M.T.H., and National Institutes of Health Grants NS31556 to D.L.F. and NS33553 to M.K.O. We thank H.-U. Klatt and A. Sharp for excellent technical assistance.

Correspondence should be addressed to Douglas L. Feinstein, Department of Anesthesiology, University of Illinois, 1819 West Polk Street, MC 519/Room 544, Chicago, IL 60612. E-mail: dlfeins@uic.edu.

Copyright (ㄷ) 2002 Society for Neuroscience $0270-6474 / 02 / 222434-09 \$ 15.00 / 0$
}

ment. In control animals, injection of $A \beta$ induced iNOS primarily in microglial cells, whereas in DSP4-treated animals, iNOS was localized to neurons, as is observed in AD brains. Injection of $\mathrm{A} \beta$ increased IL-1 $\beta$ expression initially in microglia and at later times in astrocytes, and expression levels were greater in DSP4-treated animals than in controls. The potentiating effects of DSP4 treatment on iNOS and IL- $1 \beta$ expression were attenuated by coinjection with NE or the $\beta$-adrenergic receptor agonist isoproterenol. These data demonstrate that LC loss and NE depletion augment inflammatory responses to $A \beta$ and suggest that LC loss in AD is permissive for increased inflammation and neuronal cell death.

Key words: nitric oxide; amyloid; Alzheimer's disease; cytokines; locus ceruleus; interleukin
NE may have additional functions apart from its role as a classic neurotransmitter. In astrocytes, NE blocked major histocompatibility complex class II (Frohman et al., 1988), tumor necrosis factor- $\alpha$ (Hu et al., 1991), and interleukin (IL)- $1 \beta$ (Willis and Nisen, 1995) expression and inhibited expression of the inducible isoform of nitric oxide synthase (iNOS) (Feinstein, 1998; Galea and Feinstein, 1999). NE also inhibits inflammatory activation of microglial cells (Lee et al., 1992; Loughlin et al., 1993; Chang and Liu, 2000). It has therefore been suggested that NE plays a role as an endogenous anti-inflammatory agent (Frohman et al., 1988; for review, see Feinstein et al., 2001). In light of recent findings that neuroinflammatory events contribute to AD pathology (Mrak et al., 1995; Stewart et al., 1997; Akiyama et al., 2000), we reasoned that LC cell death and loss of NE-mediated anti-inflammatory protection could exacerbate inflammatory events contributing to the pathogenesis of AD. In this study, we demonstrate that experimentally induced loss of LC neurons increases the response of cortical LC projection areas to inflammatory changes induced by $\mathrm{A} \beta$, including the appearance of neuronal iNOS expression, which has been described in AD (Vodovotz et al., 1996; Lee et al., 1999; Heneka et al., 2001). These results therefore establish a link between classic AD pathology and neuroinflammatory events.

\section{MATERIALS AND METHODS}

Animals. Male Sprague Dawley rats (Charles River Laboratories, Wilmington, MA) weighing 250-300 gm were housed in groups of four under standard conditions at $22^{\circ} \mathrm{C}$ and a $12 \mathrm{hr}$ light/dark cycle with access to food and water ad libitum.

Pretreatment and injection of immunostimulants. Rats received two intraperitoneal injections (1 week apart) of either $N$-(2-chloroethyl)- $N$ - 
A
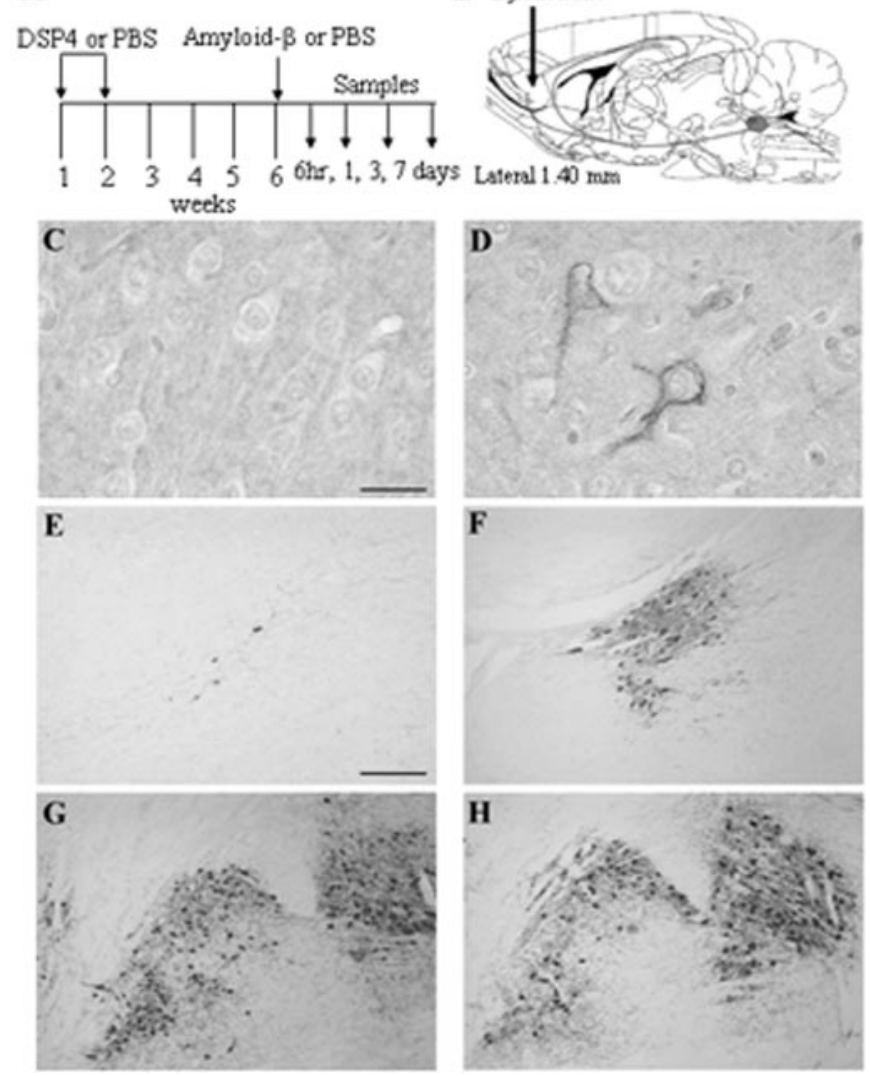

Figure 1. DSP4 induces NE depletion and LC cell loss. Rats received two injections of DSP4 1 week apart $(A)$, followed 4 weeks later by intracortical injection of $\mathrm{A} \beta$ or saline $(B)$. Serial sections from DSP4treated rats $(C, E, G)$ and control rats $(D, F, H)$ were prepared $1 \mathrm{~d}$ later for immunocytochemistry and stained for NE $(C, D)$ or TH $(E-H)$. $C, D$, Sections from the frontal cortex. $E, F$, Sections from the area of the LC. $G, H$, Sections from the area of the substantia nigra. Staining was performed on sections obtained from three animals in each group; representative images are shown. Scale bars: $C, D, 25 \mu \mathrm{M} ; E-H, 50 \mu \mathrm{M}$.

ethyl-2 bromobenzylamine (DSP4; $50 \mu \mathrm{g} / \mathrm{kg}$ ) dissolved in PBS or PBS alone (Fig. $1 A$ ). Four weeks after the second treatment, the animals were anesthetized with pentobarbital $(50 \mathrm{mg} / \mathrm{kg}$, i.p.), and placed in a stereotaxic frame (Stoelting, Wood Dale, IL) on a heating blanket. Body temperature was maintained at $37 \pm 0.5^{\circ} \mathrm{C}$ for the time of surgery. After exposure of the skull, holes were drilled bilaterally at the injection sites, and $2 \mu \mathrm{l}$ of a mixture containing aggregated $\mathrm{A} \beta_{1-42}(0.5 \mu \mathrm{g} / \mu \mathrm{l})$ was injected over a period of $120 \mathrm{sec}$ into each cortical hemisphere using a 2 $\mu \mathrm{l}$ Hamilton syringe at anteroposterior +2.0 , lateral \pm 2.5 , and ventral 3.0 $\mathrm{mm}$ relative to the bregma (Paxinos et al., 1985). Controls received $2 \mu \mathrm{l}$ of PBS. At $6 \mathrm{hr}, 1 \mathrm{~d}, 3 \mathrm{~d}$, and $7 \mathrm{~d}$ after injections, animals were killed by an overdose of pentobarbital, and brains were removed. The cortical region of the right hemisphere was homogenized in Trizol reagent (Sigma, St. Louis, MO), and RNA was isolated according to recommended procedures. The left hemisphere was immersed in $20 \mathrm{ml}$ of fixative containing $10 \%$ formaldehyde, $10 \%$ acetic acid, and $80 \%$ methanol $(\mathrm{v} / \mathrm{v} / \mathrm{v})$ for $72 \mathrm{hr}$ at room temperature and embedded in paraffin. All experiments were performed in accordance with the Declaration of Helsinki and the animal welfare guidelines and laws of the United States and were approved by the local ethical committee for animal experiments.

Processing of brains for immunohistochemistry. Immunohistochemistry was performed as described previously (Heneka et al., 1999a). Serial coronal sections of $8 \mu \mathrm{m}$ thickness were cut with a Leitz (Wetzlar, Germany) microtome and mounted on poly-L-lysine-coated slides. Slides were immersed in $10 \mathrm{~mm}$ citrate buffer, $\mathrm{pH}$ 6.0, heated in a microwave oven for four cycles of 5 min each to unmask antigen sites, and then cooled and washed in PBS. For cyclooxygenase 2 (COX-2), antigen retrieval was performed in $50 \mathrm{~mm}$ Tris- $\mathrm{HCl}, \mathrm{pH} \mathrm{9.0,} \mathrm{for} 40 \mathrm{~min}$ at $190^{\circ} \mathrm{C}$, followed by rinses in PBS and $10 \mathrm{~min}$ of incubation in cold methanol. Endogenous peroxidase activity was inhibited by rinsing slides in $0.1 \%$ hydrogen peroxide for $10 \mathrm{~min}$. Nonspecific binding was blocked by $10 \%$ normal goat serum in PBS for $1 \mathrm{hr}$ at room temperature. After washing in PBS, sections were incubated overnight at $4^{\circ} \mathrm{C}$ with the following primary antibodies (Abs): (1) anti-iNOS monoclonal Ab (mAb) N32020 (1:200 dilution; Transduction Laboratories, Lexington, KY), (2) antiIL-1 $\beta$ mAb AF501N (1:200; R\&D Systems, Wiesbaden, Germany), (3) anti-glial fibrillary acidic protein (GFAP) mAb MCA 363 (1:200; Serotec, Darmstadt, Germany), (4) anti-ED1 mAb MCA 341 (1:100; Serotec), (5) anti-tyrosine hydroxylase mAb (1:1000; DiaSorin, Stillwater, MN), (6) anti-NE-glutaraldehyde conjugate polyclonal Ab (1:600, MoBiTec, Göttingen, Germany); and (7) anti-COX-2 affinity-purified polyclonal $\mathrm{Ab}$ 160126 (1:1000; Cayman Chemical, Ann Arbor, MI). Sections were washed extensively with PBS and subsequently incubated with biotinylated or fluorescently labeled anti-rabbit or anti-mouse IgG (1:200 dilution; Vector Laboratories, Burlingame, CA) for $30 \mathrm{~min}$ at room temperature. Immunohistochemical localization was performed using the avidin-biotin peroxidase complex method (ABC kit; Vector Laboratories) with $3,3^{\prime}$-diaminobenzidine as chromogen or by confocal laser microscopy.

Negative controls included use of nonspecific IgG instead of the primary antibodies, preabsorption of primary antibodies with the respective cognate peptides (150-200 $\mu \mathrm{g}$ of peptide per milliliter of antibody working solution), and absence of immunoreactivity in PBS-injected animals and noninjected contralateral hemispheres.

Confocal laser scanning microscopy. Double-labeled specimens were analyzed with a confocal laser scanning microscope (Multiprobe 2001; Molecular Probes, Inc., Eugene, OR) equipped with an $\mathrm{Ar} / \mathrm{Kr}$ laser with balanced emission at 488, 568, and $647 \mathrm{~nm}$. To achieve an optimal signal-to-noise ratio for each fluorophore, sequential scanning with 568 and $488 \mathrm{~nm}$ was used. The digitalized images were then processed with ImageSpace 3.10 software (Molecular Probes, Inc.) on a Silicon Graphics (Mountain View, CA) power series 310GTX work station. Original section series were subjected to Gaussian filtration to reduce noise and enhance weakly but specifically labeled parts. Original and filtered sections were projected on one plane using a maximum-intensity algorithm and in some cases using depth-coding and surface-rendering algorithms.

Quantification of immunohistochemistry. Quantitative analysis of cells that stained positively for iNOS, COX-2, GFAP, and IL- $1 \beta$ was performed on brain sections from four animals from each group. Antigens were detected in five sections having a defined distance relative to the level of cortical injection. The sections were the middle section corresponding to the level of injection and four sections taken at a distance of 35 and $70 \mu \mathrm{m}$ rostral and caudal to the injection site. The number of cells within the respective fields was determined using a counting grid, and cells within the needle tract were not counted.

$R N A$ preparation and reverse transcription PCR. Total RNA was extracted from brain samples using Trizol reagent according to the manufacturer's instructions (Sigma), and reverse transcription (RT)-PCR was performed as described previously (Heneka et al., 2000). The primers used were: iNOS forward, 5'-CTGCATGGAACAGTATAAGGCAAAC-3'; iNOS reverse, 5'-CAGACAGTTTCTGGTCGATGTCATGA-3'; IL-1 $\beta$ forward, 5'-GCTACCTATGTCTTGCCCGTGGAG-3'; IL-1 $\beta$ reverse, 5'-GTCCCGACCATTGCTGTTTCCTA-3'; COX-2 forward, 5'-TCCCGGATCCCCAAGGCACAAATA-3'; COX-2 reverse, 5'-TCAGACCCGGCACCAGACCAAAGA-3'; glyceraldehyde 3-phosphate dehydrogenase $(\mathrm{GDH})$ forward, 5'-ACGACAGTCCATGCCATCAC-3'; GDH reverse, 5'-TCCACCACCCTGTTGCTGTA-3'; IL-6 forward, 5' CTTGGGACTGATGTTGTTGA-3'; and IL-6 reverse, 5'-CTCTGAATGACTCTGGCTTTG-3'.

PCR conditions were 35 cycles of denaturation at $95^{\circ} \mathrm{C}$ for $30 \mathrm{sec}$, annealing at $63^{\circ} \mathrm{C}$ for $45 \mathrm{sec}$, and extension at $72^{\circ} \mathrm{C}$ for $45 \mathrm{sec}$. For iNOS, a 40 bp smaller internal iNOS standard was included in the PCR mixture to facilitate quantification. PCR products were separated by electrophoresis through $2 \%$ agarose containing $0.5 \mu \mathrm{g} / \mathrm{ml}$ ethidium bromide and imaged using an AlphaInotech imaging system (Temecula, CA); band intensities were determined using ImageJ software from the National Institutes of Health (Bethesda, MD). For iNOS calculations, the band intensities of the cDNA product were compared with those of the internal standard. PCRs were performed on RNA prepared from three different animals in each group; representative gels are shown.

Data analysis. Quantitative immunostaining and PCR data were analyzed by one-way or two-way ANOVA with Bonferroni's multiple com- 
parison post tests using Prism version 3.00 software (GraphPad Software, San Diego, CA).

\section{RESULTS}

Examination of brain sections prepared 5 weeks after DSP4 treatment showed a marked loss of LC neurons in DSP4 animals compared with animals injected with PBS as revealed by decreased tyrosine hydroxylase staining (Fig. $1 E, F$ ) and decreased $\mathrm{NE}$ immunoreactivity in the cortex (Fig. 1C,D). DSP4 effects were restricted to the LC, because tyrosine hydroxylase staining of substantia nigral neurons was essentially the same in DSP4treated as in PBS-treated animals (Fig. $1 G, H$ ).

At 4 weeks after the second DSP4 treatment, rats were injected in the frontal cortex with $\mathrm{A} \beta$ or PBS (Fig. $1 B$ ). Injection of $\mathrm{A} \beta$ into control animals increased iNOS mRNA levels beginning $6 \mathrm{hr}$ after injection; iNOS mRNA reached maximal levels after $1 \mathrm{~d}$, and levels diminished but were still detectable after $3 \mathrm{~d}$ (Fig. 2). A similar pattern of iNOS mRNA accumulation occurred after injection of $\mathrm{A} \beta$ into DSP4-treated animals; however, at all times, the levels attained were higher than those in control animals (Fig. 2). Injection of PBS alone into either control or DSP4 animals induced little or no detectable amounts of iNOS mRNA. Semiquantitative competitive PCR indicated that compared with injection with PBS, A $\beta$ increased iNOS mRNA levels approximately ninefold in DSP4 animals after $6 \mathrm{hr}$, compared with only a $20 \%$ increase in control animals $(n=3$ each; $p<0.01)$; at $1 \mathrm{~d}$, $\mathrm{A} \beta$ increased levels $\sim 36$-fold in DSP4 animals compared with $\sim 24$-fold in control animals $(n=3$ each; $p<0.001)$ (Fig. $2 B)$. The iNOS mRNA levels decreased at day 3 and decreased further at day 7, at which point iNOS mRNA was present at low but similar amounts in both groups ( $p>0.05$; unpaired $t$ test).

The levels of IL-1 $\beta$ mRNA were also increased in response to A $\beta$ injection (Fig. 2). As observed for iNOS, IL-1 $\beta$ mRNA levels were consistently higher in DSP4-treated animals compared with controls, with maximal levels detected $1 \mathrm{~d}$ after injection (Fig. 2). Densitometric analysis showed that after $1 \mathrm{~d}, \mathrm{~A} \beta$ increased IL- $1 \beta$ mRNA levels 4.5-fold in DSP4 animals versus 1.4-fold in control animals $(n=3$ each; $p<0.001)$. As was the case for iNOS, IL- $1 \beta$ mRNA levels decreased at $3 \mathrm{~d}$ and decreased further at $7 \mathrm{~d}$, although at this point the IL- $1 \beta$ mRNA levels were still greater in DSP4-treated versus control animals ( $p<0.05$; unpaired $t$ test). Similarly, IL- 6 mRNA levels were increased by A $\beta$ and increased to a greater extent in DSP4-treated versus control animals. However, the increase in IL-6 levels was transient, with a significant increase observed only at $6 \mathrm{hr}$, the earliest time investigated. In contrast, $A \beta$ injection showed little effect on the mRNA levels of either COX-2 (levels were slightly elevated by DSP4 at day 1 and slightly attenuated at 3 d compared with control levels) or GDH (a small decrease was observed in DSP4 animals vs controls on day 7).

At $1 \mathrm{~d}$ after $\mathrm{A} \beta$ injection, iNOS protein was detected in two different cell types. In control animals, iNOS was restricted primarily to microglial cells (Fig. 3B), whereas in DSP4-treated animals, iNOS was detected predominantly in pyramidal cortical neurons (Fig. 3A). Injection of saline into control or DSP4-treated animals did not lead to iNOS expression (Fig. 3C), ruling out cross-reaction of the antibody used with other NOS isoforms and consistent with our previous findings that the antibody used detects a protein of $\sim 130,000 \mathrm{Da}$ in immunostimulated but not control rat brain samples (Heneka et al., 2000, 2001). Parenchymal iNOS-positive microglia were scattered throughout the frontal cortex and occasionally observed in close proximity to brain

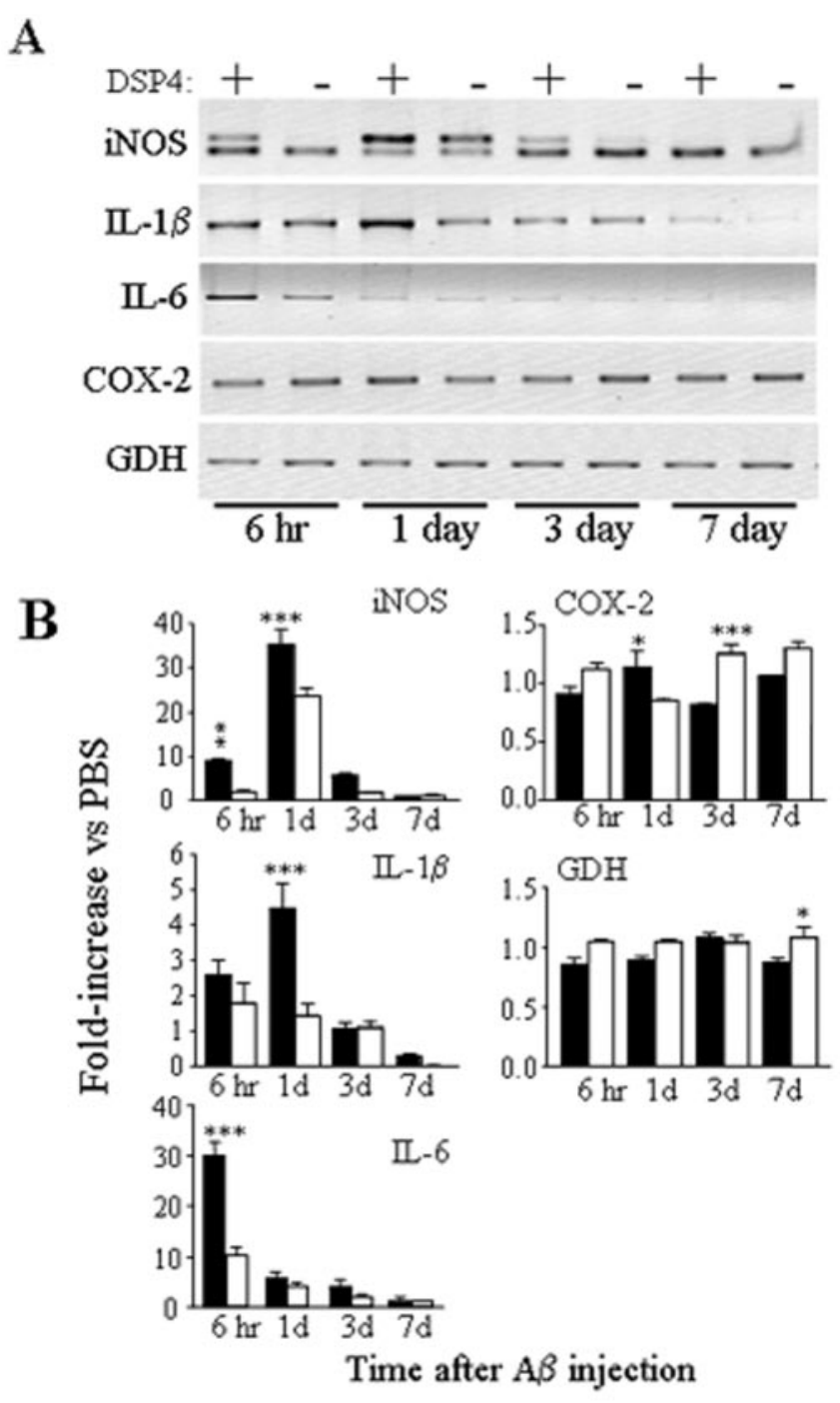

Figure 2. Inflammatory gene transcription in DSP4-treated animals and controls. $A$, Total RNA was prepared from cortices of DSP4-treated (+) and control ( - ) rats at the indicated times after intracortical injection of $\mathrm{A} \beta$ and examined by RT-PCR for iNOS, IL- $1 \beta, \mathrm{COX}-2$, and GDH mRNAs. For iNOS, PCRs were performed in the presence of $20 \mathrm{fg}$ of a specific iNOS internal standard that yields a PCR product $40 \mathrm{bp}$ smaller than the band derived from the iNOS cDNA. RT-PCRs were performed using RNA samples isolated from three animals in each group; representative gels are shown. $B$, Densitometric analysis of band intensities from three independent experiments. Filled bars, DSP4 animals; open bars, control animals. Data are the fold increase attributable to $\mathrm{A} \beta$ injection versus that attributable to saline injection (mean \pm SEM). ${ }^{*} p<0.05$; ${ }^{* *} p<0.01 ; * * p<0.001$; DSP4-treated animals versus controls.

vessels (Fig. 3B, inset). Quantification revealed similar numbers of iNOS-positive microglial cells in control and DSP4-treated animals (Fig. $3 J$ ). In contrast, the number of iNOS-immunopositive neurons was significantly increased in the DSP4 group. Confocal laser microscopy of an area near the injection site revealed costaining of the majority (but not all, as indicated by arrows in Fig. $3 F$ ) of neurons for neuron-specific enolase (NSE) and iNOS in DSP4 animals and costaining of microglial cells for ED1 and iNOS in control animals (Fig. 3G-I).

Immunocytochemical staining also revealed two cell types expressing IL- $1 \beta$. At $1 \mathrm{~d}$ after $\mathrm{A} \beta$ injection, IL- $1 \beta$ was detected exclusively in microglial cells. Ramifications to oval or rounded 

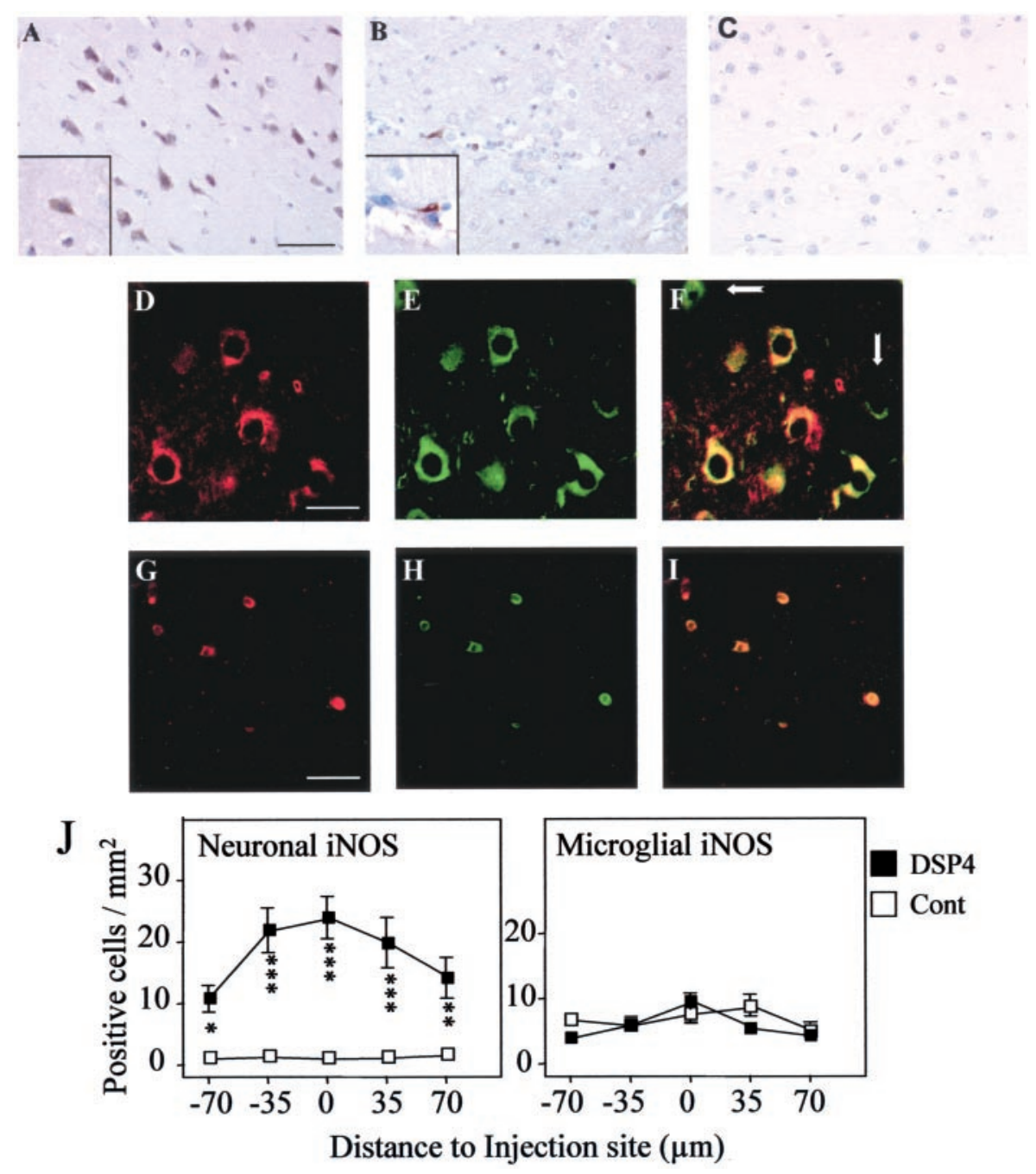

Figure 3. Immunohistochemical localization of iNOS. Serial sections were prepared from brains of DSP4-treated $(A, C)$ and control $(B)$ rats at $1 \mathrm{~d}$ after injection of $\mathrm{A} \beta(A, B)$ or saline $(C)$ and stained with antibody to iNOS; immunoreactivity was detected by the DAB method. $A$, The inset shows a positively stained cell with neuronal morphology. $B$, The inset shows a positively stained cell with microglial morphology. Cellular identification of iNOS staining was obtained by confocal laser microscopy of sections costained with antibodies to iNOS $(D, G)$ and either NSE to detect neurons $(E)$ or ED1 to detect microglial cells $(H) . F, I$, Overlapping fluorescent signals; some NSE-positive, iNOS-negative neurons are indicated by white arrows. Scale bars: $A, B, 50 \mu \mathrm{m}$; $D-I, 25 \mu \mathrm{m}$. The images shown are representative of sections obtained from three different animals in each group. $J$, Staining was quantified by counting the number of neurons (left) and microglia (right) positively stained for iNOS in five serial sections. The data are the mean \pm SEM of four animals in each group. ${ }^{*} p<0.05 ; * * p<0.005$; ${ }^{* * *} p<0.0005$; DSP4-treated animals versus controls. microglia cells were observed, suggesting different states of activation (Fig. 4A,B). Quantification revealed that DSP4-treated animals had a significantly higher number of IL-1 $\beta$ immunopositive microglial cells than PBS controls (Fig. $4 L$, left). IL-1 $\beta$ was not detected in saline-injected animals (data not shown). Confocal microscopy using ED1 for microglia detection revealed the morphological nature of the IL- $1 \beta$-immunopositive cells (Fig. $4 C-E$ ). The number of more highly arborized and ramified microglia appeared to be higher in control versus DSP4treated animals, suggesting a lesser degree of microglial activation in controls.

In contrast to the microglial localization observed at $1 \mathrm{~d}$, after $7 \mathrm{~d}$ the IL-1 $\beta$ was detected almost exclusively in GFAP-positive astrocytes (Fig. 4). Although essentially all GFAP-positive cells proximal to the injection site were also IL-1 $\beta$-positive (Fig. $4 F-$ $H$ ), distally located GFAP-positive cells (Fig. $4 J$ ) were IL- $1 \beta$ negative (Fig. 4I,K), suggesting that not all astrocytes undergoing gliosis are able to express IL- $1 \beta$ and ruling out the possibility that activated astrocytes show a nonspecific high avidity for the IL-1 $\beta$ antibody. As found for microglia at $24 \mathrm{hr}$, the DSP4-treated animals showed a higher number of IL-1 $\beta$-positive astrocytes at $7 \mathrm{~d}$ than did PBS controls (Fig. $4 L$, right).

IL-6 expression examined at $1 \mathrm{~d}$ after $\mathrm{A} \beta$ injection was localized primarily to pyramidal neurons in DSP4-treated (Fig. $5 A$ ) and to a much lesser extent in control (Fig. $5 B$ ) animals (Fig. $5 E$, right). IL-6-positive neurons were observed throughout the cortex but were significantly increased around the injection site. Similarly, cortical neurons were also the primary site of COX-2 expression (Fig. 5C,D), and no differences were observed in the cellular localization between DSP4-treated and control rats. Quantification of COX-2-immunopositive neurons revealed no significant differences between DSP4-treated and control groups (Fig. $5 C$ ). In addition to neurons, COX-2 was also observed in endothelial cells and to a minor extent in activated glial cells (data not shown).

Injection of $\mathrm{A} \beta$ strongly increased the number of GFAPpositive cells in the cortex (and in the nearby corpus callosum; data not shown) compared with PBS injection at both time points investigated ( $24 \mathrm{hr}$ and $7 \mathrm{~d}$ ). In both brain regions, the DSP4treated animals (Fig. 6B) showed a higher number of GFAPpositive cells than did control rats (Fig. $6 \mathrm{~A}$ ), and this increase was statistically significant within the cortex (Fig. $6 C$ ).

In DSP4-treated animals, coinjection with NE partially reversed the $\mathrm{A} \beta$-dependent increase of both iNOS and IL- $1 \beta$ mRNA levels (Fig. 7A). As expected, injection of $\mathrm{A} \beta$ significantly increased iNOS mRNA levels $(21.7 \pm 0.5$-fold vs noninjected levels), and this effect was significantly reduced (to $8.6 \pm 0.3$-fold vs noninjected levels) by NE ( $n=3$ each; $p<$ 0.0001 ) and by $\sim 30 \%$ (to $15.2 \pm 1.8$-fold control levels) by coinjection of the $\beta$-adrenergic receptor agonist isoproterenol 

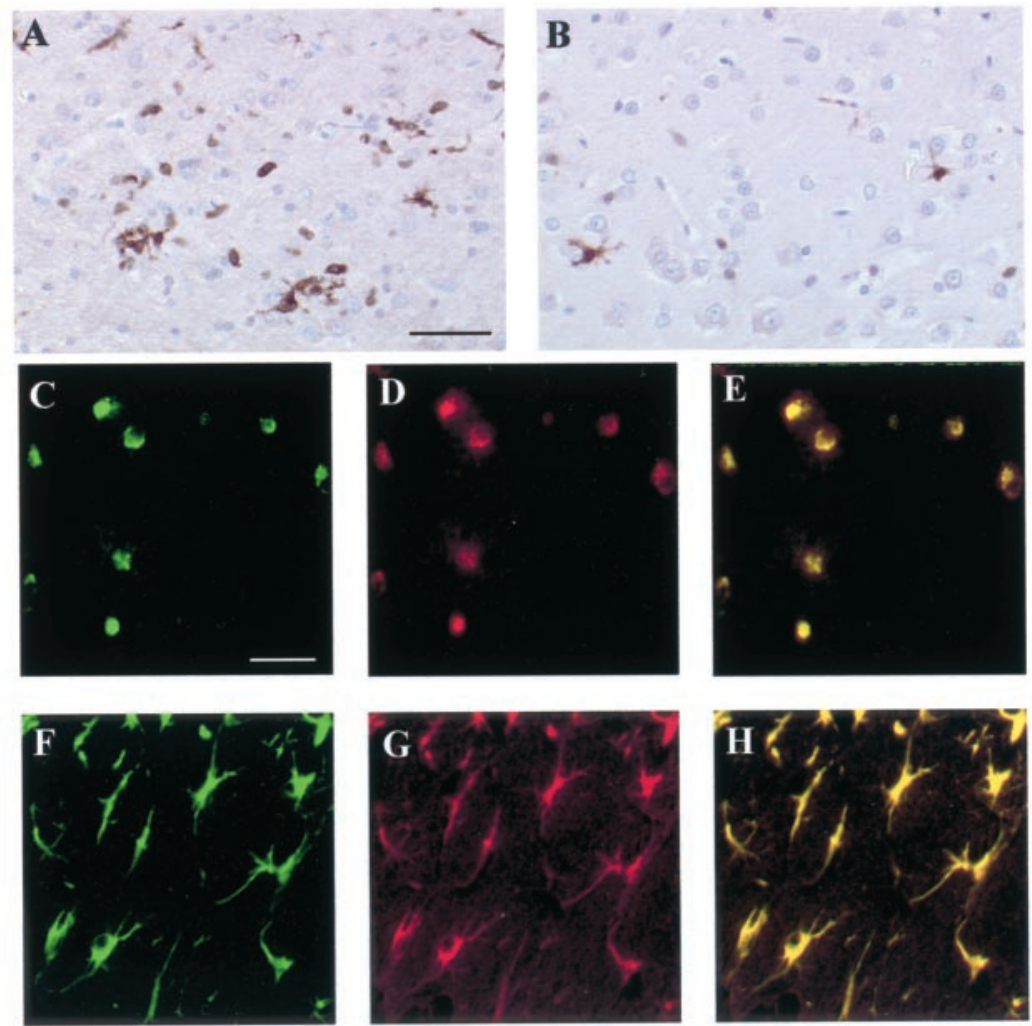

Figure 4. Immunohistochemical localization of IL-1 $\beta$. Serial sections were prepared from brains of DSP4treated $(A)$ and control $(B)$ rats at $1 \mathrm{~d}$ after injection of $\mathrm{A} \beta$ and stained with an antibody to IL- $1 \beta$; immunolabeling was detected by the DAB method. Limited staining was observed in control sections, if the primary antibody was omitted, or if the primary antibody was preincubated with a blocking peptide. Cellular identification was obtained by confocal laser microscopy of sections costained with antibodies to IL- $1 \beta(C, F, I)$ and either ED1 to detect microglia at $1 \mathrm{~d}(D)$ or GFAP to detect astrocytes at $7 \mathrm{~d}(G, J) . A-H$ are from sections taken $35 \mu \mathrm{m}$ from the injection site; $I-K$ are from sections take $70 \mu \mathrm{m}$ from the injection site. $E, H, K$, Overlapping fluorescent signals. Scale bars: $A, B, 50$ $\mu \mathrm{m} ; C-K, 25 \mu \mathrm{m}$. Images are representative of sections obtained from three different animals in each group. $L$, Staining was quantified by counting the number of microglia (left, $1 \mathrm{~d})$ and astrocytes (right, $7 \mathrm{~d}$ ) positively stained for iNOS in five serial sections. The data are the mean \pm SEM of four animals in each group. ${ }^{*} p<0.05$; ${ }^{* *} p<0.005 ; * * * p<0.0005$; DSP4-treated animals versus controls.
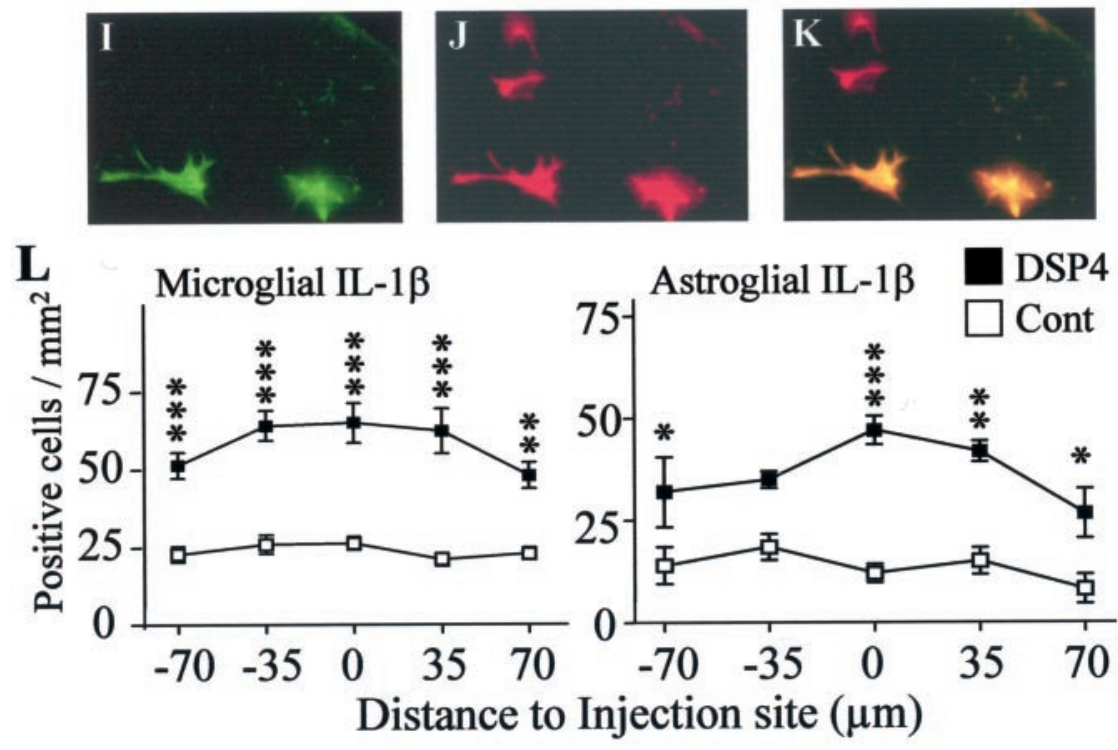

$(n=3$ each; $p<0.001)$. Similarly, $\mathrm{A} \beta$ increased IL $-1 \beta$ mRNA levels (to $2.0 \pm 0.1$-fold of control levels), and those levels were significantly $(p<0.001)$ reduced by $\sim 40 \%$ by $\mathrm{NE}$ or by isoproterenol. In contrast, coinjection of $\mathrm{NE}$ (or of isoproterenol; data not shown) had no effect on the increase of iNOS and IL- $1 \beta$ mRNA levels after $\mathrm{A} \beta$ injection into control animals $(9.3 \pm 0.2$-fold and $1.3 \pm 0.1$-fold vs control levels for iNOS and IL-1 $\beta$, respectively) (Fig. $7 B$ ). The mRNA levels of $\mathrm{GDH}$ (and of COX-2; data not shown) were not affected by injection of $\mathrm{NE}$ or isoproterenol. Coinjection of $\mathrm{NE}$ or of isoproterenol also reduced the appearance of neurons that stained positive for iNOS after $\mathrm{A} \beta$ injection into DSP4-treated animals (Fig. 7C).

\section{DISCUSSION}

Our results for the first time establish a link between two classic pathological hallmarks of AD, namely LC loss and decreased noradrenergic innervation, and the recent understanding that neuroinflammatory events contribute to neuronal dysfunction and cell death in AD (Akiyama et al., 2000). Our findings suggest a causative relationship between LC loss and the extent of projection area neuronal damage incurred in response to inflammatory stimuli. Furthermore, whereas iNOS expression in glial cells has been described in several animal models of $\mathrm{AD}$, to the best of our knowledge this is the first example in which $A \beta$ induced neuronal iNOS expression, which is observed in AD (Vodovotz et al., 1996; Lee et al., 1999). 

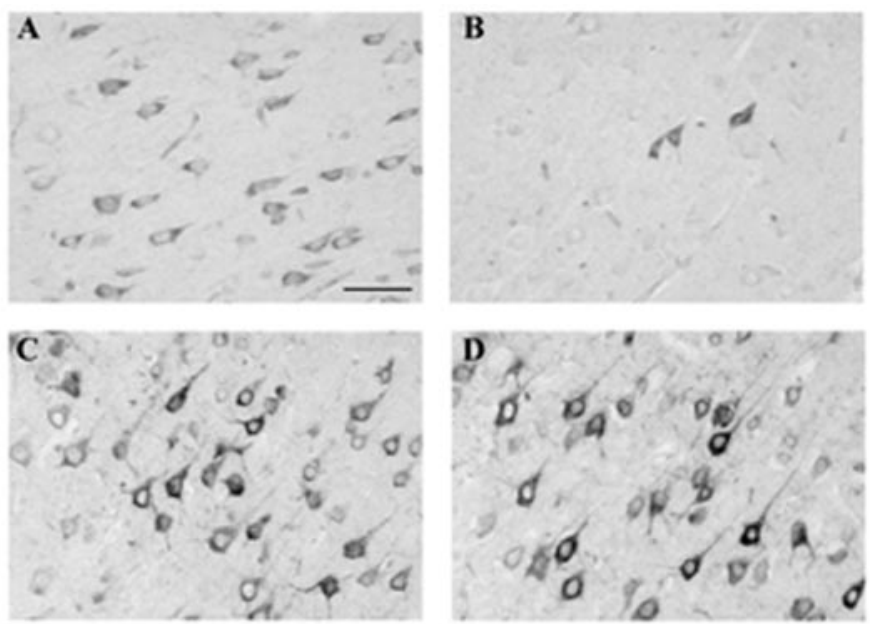

$\mathbf{E}$

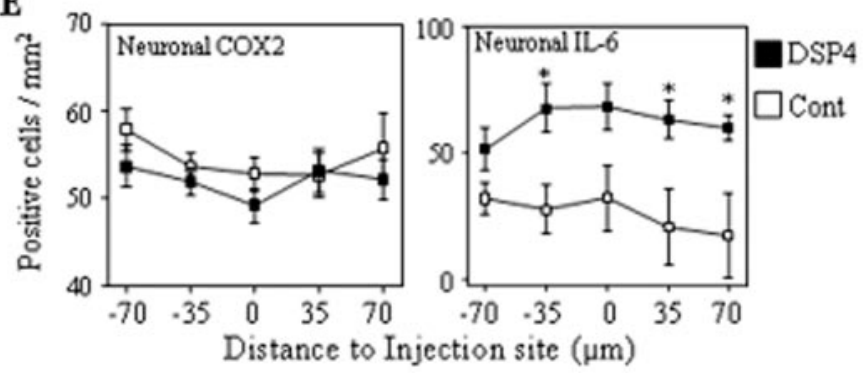

Figure 5. Immunohistochemical localization of IL-6 and COX-2. Serial sections were prepared from brains of DSP4-treated $(A, C)$ and control $(B, D)$ rats at $1 \mathrm{~d}$ after injection of $\mathrm{A} \beta$ and were stained with antibodies to IL-6 $(A, B)$ or COX-2 $(C, D)$; immunolabeling was detected by the DAB method. Scale bar, $50 \mu \mathrm{m}$. The images shown are representative of sections obtained from three different animals in each group. $E$, Staining was quantified by counting the number of neurons positively stained for COX-2 (left) or IL-6 (right) in five serial sections. The data are the mean \pm SEM of four animals in each group. ${ }^{*} p<0.05$; DSP4-treated animals versus controls.

Neuronal cell death of aminergic brainstem nuclei such as the LC and the dorsal raphe nucleus is a well defined feature of AD pathology (Mann et al., 1983; Wilcock et al., 1988; Forno, 1992). The LC is located in the pontine tegmentum and serves as the main subcortical site for the synthesis of NE (Freedman et al., 1975). Ascending noradrenergic axons project to the hippocampus, to the frontal and entorhinal cortex, and to a minor extent to various other brain regions. Each LC neuron sustains a widely divergent axon that innervates a large terminal field. Axon terminals are found in close contact to neurons, astrocytes, and microglia, suggesting that $\mathrm{NE}$ acts as a neuromodulator influencing a circumscribed microenvironment rather than as a classic neurotransmitter (Seguela et al., 1990; German et al., 1992).

In $\mathrm{AD}$, the central portion of the $\mathrm{LC}$, which projects predominantly to the hippocampus, frontal cortex, and temporal cortex (areas that are usually severely affected by senile plaque and neurofibrillary tangle formation), shows the most extensive loss of cells (Marcyniuk et al., 1986). LC loss and the degeneration of ascending noradrenergic axons leads to decreased NE levels in respective projection areas (Adolfsson et al., 1979; Iversen et al., 1983), whereas adrenergic receptors are upregulated in response to the noradrenergic deafferentation (Kalaria et al., 1989b). Since the initial neuropathological descriptions of LC loss, several studies have demonstrated a significant correlation between LC cell death or decreased cortical NE levels and the severity and dura-
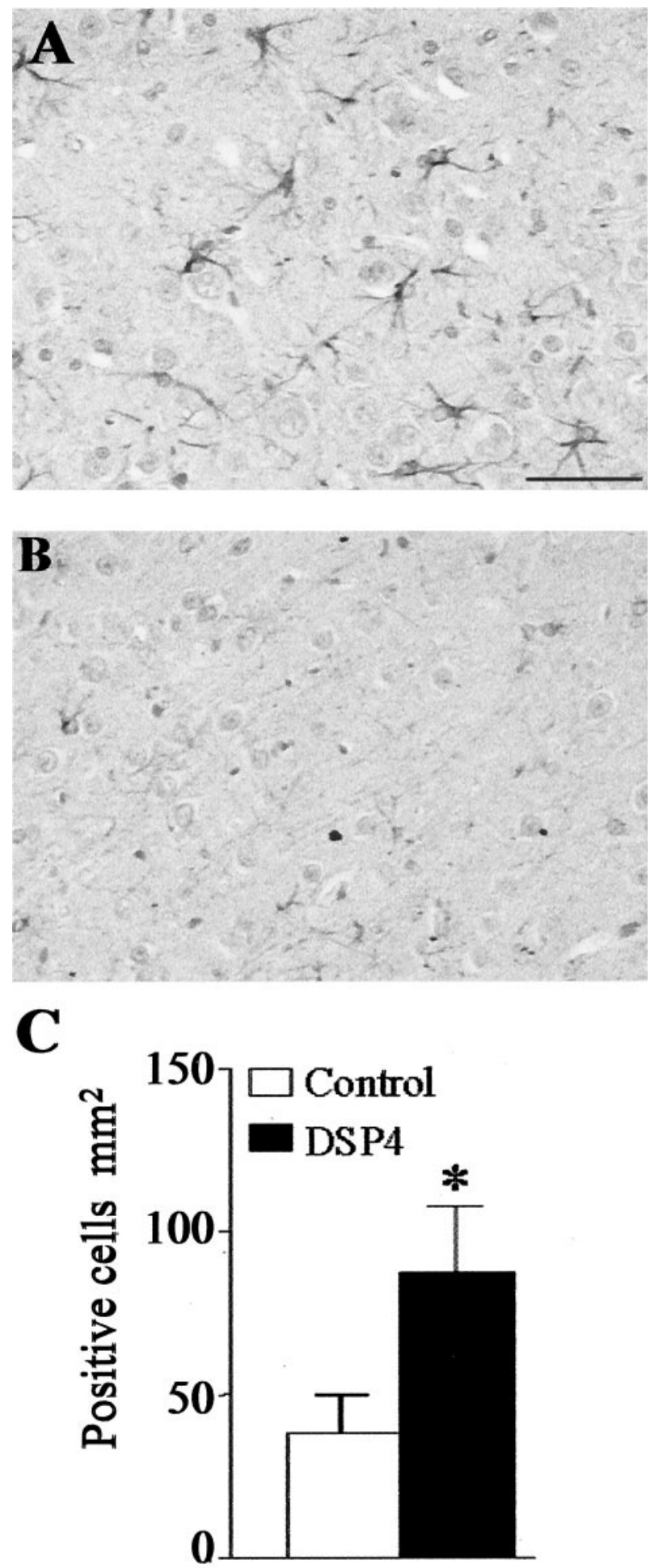

Figure 6. Effect of DSP4 treatment on GFAP expression. Serial sections were prepared from the frontal cortex of DSP4-treated $(A)$ and control $(B)$ rats at $1 \mathrm{~d}$ after injection of $\mathrm{A} \beta$ and stained with an antibody to GFAP; immunolabeling was detected by the DAB method. Scale bar, 50 $\mu \mathrm{m}$. The images shown are representative of sections obtained from three different animals in each group. $C$, Staining was quantified by counting the average number of GFAP positively stained astrocytes in five serial sections. The data are the mean \pm SEM of four animals in each group. ${ }^{*} p<0.05$; DSP4-treated animals versus controls. 
A
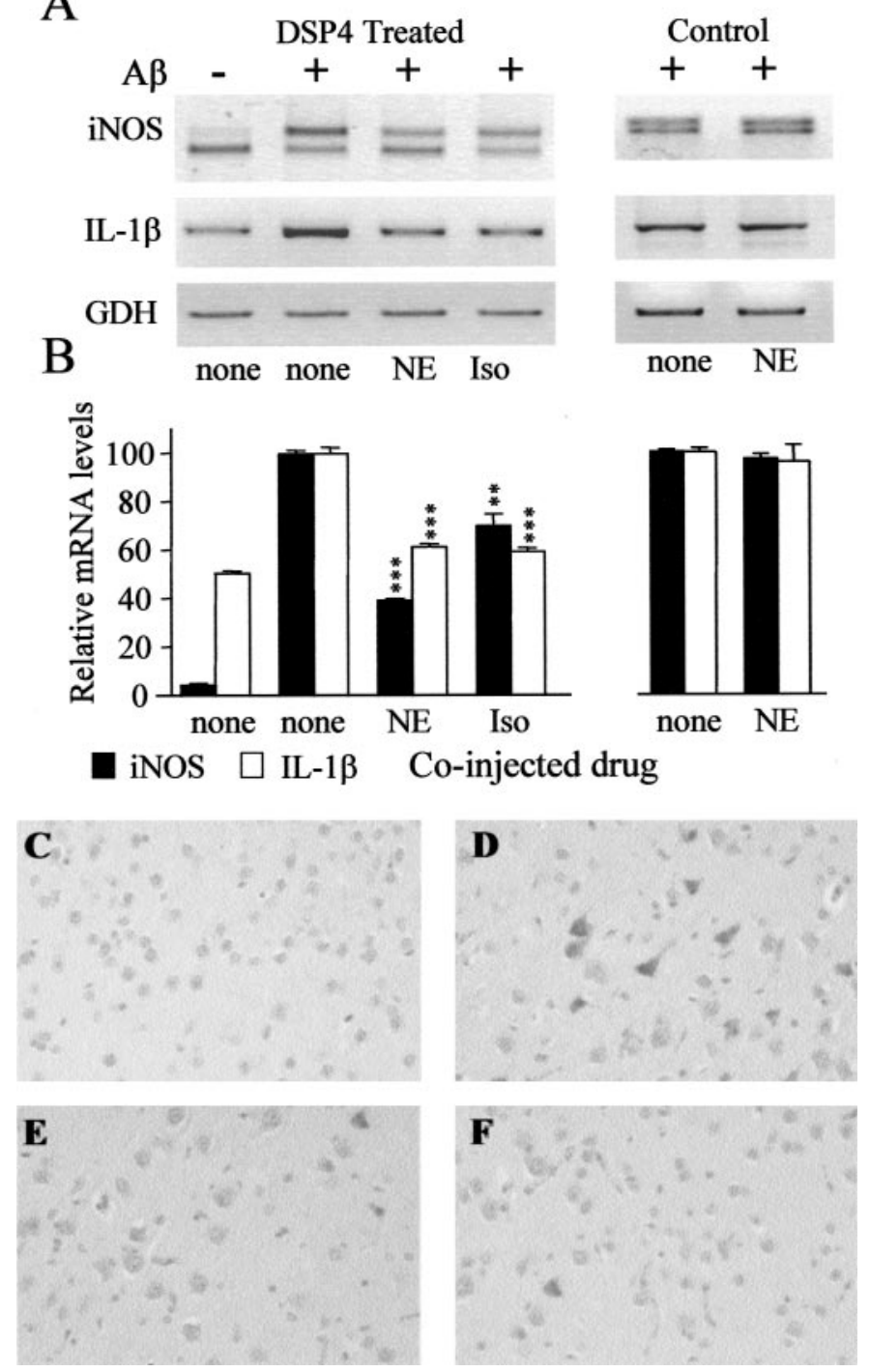

Figure 7. Effect of NE on DSP4 potentiation of iNOS and IL-1 $\beta$ expression. Total RNA was prepared from frontal cortices of DSP4-treated (left) and control (right) rats at $1 \mathrm{~d}$ after injection of $\mathrm{A} \beta$ (or saline, none) together with a $100 \mathrm{nM}$ concentration of $\mathrm{NE}(+N E)$ or isoproterenol ( + Iso). Equal aliquots were converted to cDNA and assayed by competitive RT-PCR for iNOS and RT-PCR for IL- $\beta$ and GDH. $A$, Representative gel. $B$, Quantitative analysis performed on band intensities obtained using ImageJ software. Values shown are for mRNA levels relative to those measured in samples from $A \beta$-injected animals and are the mean \pm SD of three animals in each group. The $100 \%$ values correspond to fold increases of $21.7 \pm 0.5$ (iNOS in DSP4 rats), $9.3 \pm 0.2$ (iNOS in control rats), $2.0 \pm 0.1$ (IL- $1 \beta$ in DSP4 rats), and $1.3 \pm 0.1$ (IL-1 $\beta$ in control rats) versus that caused by injection of PBS. ${ }^{* *} p<0.01$; ${ }^{* *} p<0.0001$ versus injection of $\mathrm{A} \beta$ alone (one-way ANOVA; Bonferroni's multiple comparison test). $C-F$, Immunocytochemical staining for iNOS in representative cortical sections from DSP4-treated rats at $1 \mathrm{~d}$ after injection of saline $(C), \mathrm{A} \beta(D), \mathrm{A} \beta$ plus NE $(E)$, or $\mathrm{A} \beta$ plus Iso $(F)$.

tion of dementia in AD (Mann et al., 1982; Bondareff et al., 1987; German et al., 1992); however, the basis for this correlation is not clear. For example, it has been suggested that in AD, LC degeneration causes a denervation microangiopathy characterized by thickened capillary walls that compromise normal blood-brain barrier function, including nutrition of the brain parenchyma, which could contribute to generalized neuronal dysfunction (Scheibel et al., 1987). Alternatively, numerous reports indicate that NE can regulate inflammatory gene expression in brain cells through modulation of the intracellular second messenger cAMP. Our own studies (Feinstein, 1998) and those of others (Galea and Feinstein, 1999) show that NE inhibits iNOS expression in astrocytes, mediated by activation of $\beta$-adrenergic receptors and increases in cAMP.

To address the hypothesis that there is a causative link between LC loss and reduced NE content and inflammatory events in AD, we used the selective neurotoxin DSP4 (Fritschy and Grzanna, 1991) to create chemical lesions in LC neurons and reduce cortical NE levels. DSP4 has been demonstrated previously to influence neurodegenerative processes, including those induced by $N$-methyl-4-phenyl 1,2,3,6-tetrahydropyridine (Mavridis et al., 1991) and by cerebral ischemia (Nishino et al., 1991). In our studies, we used a lower concentration of DSP4 than commonly used (we injected $50 \mu \mathrm{g} / \mathrm{kg}$ twice vs a single injection of 10-50 $\mathrm{mg} / \mathrm{kg}$ ) and waited 4 weeks before additional experimentation. This treatment caused selective degeneration of noradrenergic projections and cell death of LC neurons, whereas in the same animals, we did not observe any loss of substantia nigra neurons. Thus, in the present study, DSP4 treatment provides a model reflecting the impaired state of the noradrenergic system in AD.

Our data confirm that, as observed previously (Weldon et al., 1998), intracortical injection of aggregated $\mathrm{A} \beta$ induces an inflammatory response involving microglial expression of iNOS and IL- $1 \beta$ and astrogliosis represented by increased GFAP expression. These results demonstrate that under normal physiological conditions, both neurons and glia have the capacity to respond to immunostimulation by $\mathrm{A} \beta$, although it is not known whether these responses are a direct result of cell activation by $\mathrm{A} \beta$ or are indirectly attributable to $\mathrm{A} \beta$-induced release of other proinflammatory molecules. These responses involved a limited number of cells, and increased mRNA expression returned to basal levels within $3 \mathrm{~d}$ after $\mathrm{A} \beta$ injection. The restoration to basal levels suggests that in the normal animal, autoregulatory mechanisms are invoked to reduce ongoing inflammation.

In contrast to control animals, cortical inflammatory responses in DSP4-treated animals occurred sooner, were more robust, and were of prolonged duration. Our data show that after $A \beta$ injection, the IL- $1 \beta$ mRNA was transiently expressed, with maximal levels observed after $1 \mathrm{~d}$ and much reduced levels observed at days 3 and 7 (Fig. 2). Immunocytochemical staining (Fig. 4) done at day 1 revealed IL- $1 \beta$ expression primarily in microglia, whereas at day 7 we observed strong astroglial staining in areas near the site of $\mathrm{A} \beta$ injection. Because there are much lower levels of IL- $1 \beta$ mRNA at day 7 compared with day 1 or day 3 , robust astroglial expression at day 7 might be caused by IL- $1 \beta$ protein that was translated from mRNA present at earlier times. These data also suggest that astrogliosis alone is not sufficient to induce IL- $1 \beta$ expression, because astroglial IL- $1 \beta$ was not detected at day 1 despite greatly increased GFAP levels (Fig. 6), and because we detected GFAP-positive, IL- $1 \beta$-negative cells more distal to the injection site (Fig. 4J,K). The absence of astroglial staining at day 7 using other antibodies (COX-2 or nonspecific IgG; data not shown) also suggests that nonspecific antibody binding to activated astrocytes does not account for the observed IL- $1 \beta$ staining. Although microglia have been described as the prominent IL- $1 \beta$-producing cell type in the brain (Sheng et al., 2001), there is increasing evidence that astrocytes can produce IL-1 $\beta$ both in vitro (Hu and Van Eldik, 1999; Akama and Van Eldik, 2000) and in vivo (Lee et al., 2000; Mehlhorn et al., 2000; Apelt and Schliebs, 2001). In one study using Tg2576 transgenic mice, which overex- 
press the Swedish amyloid precursor protein double mutation, IL- $1 \beta$ was detected in astrocytes near both fibrillary and diffuse amyloid plaques, whereas microglial IL-1 $\beta$ was detected only around the fibrillary plaques (Apelt and Schliebs, 2001). In contrast, in other studies with these mice, only microglial IL- $1 \beta$ was detected (Benzing et al., 1999; Sigurdsson et al., 2001).

DSP4 treatment caused an increase in A $\beta$-dependent iNOS expression that was detected at both the mRNA and protein levels. The expression of iNOS in control animals was observed primarily in activated perivascular and parenchymal microglial cells, whereas in DSP4-treated animals, iNOS was detected primarily in neurons. This is in contrast to the effects of DSP4 on IL- $1 \beta$ expression, where the expressing cells remained the same although the overall expression increased. This suggests that DSP4 treatment does not lower the threshold or increase the capacity of microglial cells to express iNOS but instead lowers the threshold and/or increases the levels of stimulatory factors needed to induce neuronal expression. Although iNOS expression in neurodegenerative disease has been described previously (Licinio et al., 1999), it is only in AD that neuronal rather than glial or endothelial expression has been observed (Vodovotz et al., 1996; Lee et al., 1999). Treatment of animals with DSP4 may therefore provide a model to further examine the regulation and consequences of neuronal iNOS in AD.

The inability of $\mathrm{A} \beta$ to induce neuronal iNOS under normal conditions could reflect a basal refractory state of these neurons that is imparted to them by the normal NE levels. Findings that intraparenchymal injection of lipopolysaccharide and cytokines into the cerebellum induces iNOS expression in cerebellar granule neurons (Heneka et al., 1999a), whereas similar injections into the cortex or striatum induce only glial iNOS (Heneka et al., 1999 b), are consistent with the idea that cortical neurons are intrinsically resistant to inflammatory activation. Diminished NE protection could therefore decrease the threshold necessary for neuronal inflammatory gene transcription in response to $\mathrm{A} \beta$ and cytokines. Alternatively, it is also possible that neuronal iNOS expression is attributable to the greater and prolonged microglial (and eventual astroglial) IL- $1 \beta$ expression that occurs in the DSP4-treated animals. Finally, DSP4 treatment may facilitate the expression and accumulation of additional cytokines, which may be required for neuronal iNOS expression.

It has been suggested that LC dysfunction occurs early in AD and precedes a retrograde degenerative process that results in a gradual loss of cortical-projecting LC neurons (German et al., 1992). This dysfunction and a subsequent decrease of NE in cortical projection areas may promote proinflammatory events evoked by $\mathrm{A} \beta$ deposition and plaque formation, thereby initiating or contributing to the above retrograde LC degeneration. We therefore hypothesize that neuronal LC loss and neuropathological and inflammatory changes are members of a vicious selfmaintaining and self-stimulating cycle. Future studies will further characterize this cycle and evaluate at which point and by what treatment a beneficial interruption of this cycle can be achieved.

\section{REFERENCES}

Adolfsson R, Gottfries CG, Roos BE, Winblad B (1979) Changes in the brain catecholamines in patients with dementia of Alzheimer type. Br J Psychiatry 135:216-223.

Akama KT, Van Eldik LJ (2000) Beta-amyloid stimulation of inducible nitric-oxide synthase in astrocytes is interleukin-1. J Biol Chem 275:7918-7924.

Akiyama H, Barger S, Barnum S, Bradt B, Bauer J, Cole GM, Cooper NR, Eikelenboom P, Emmerling M, Fiebich BL, Finch CE, Frautschy S, Griffin WS, Hampel H, Hull M, Landreth G, Lue L, Mrak R,
Mackenzie IR, McGeer PL, et al (2000) Inflammation and Alzheimer's disease. Neurobiol Aging 21:383-421.

Anlezark GM, Crow TJ, Greenway AP (1973) Impaired learning and decreased cortical norepinephrine after bilateral locus coeruleus lesions. Science 181:682-684.

Apelt J, Schliebs R (2001) Beta-amyloid-induced glial expression of both pro- and anti-inflammatory cytokines in cerebral cortex of aged transgenic Tg2576 mice with Alzheimer plaque pathology. Brain Res 894:21-30.

Benzing WC, Wujek JR, Ward EK, Shaffer D, Ashe KH, Younkin SG, Brunden KR (1999) Evidence for glial-mediated inflammation in aged APP(SW) transgenic mice. Neurobiol Aging 20:581-589.

Bondareff W, Mountjoy CQ, Roth M, Rossor MN, Iversen LL, Reynolds GP, Hauser DL (1987) Neuronal degeneration in locus ceruleus and cortical correlates of Alzheimer disease. Alzheimer Dis Assoc Disord 1:256-262.

Chang JY, Liu LZ (2000) Catecholamines inhibit microglial nitric oxide production. Brain Res Bull 52:525-530.

Feinstein DL (1998) Suppression of astroglial nitric oxide synthase expression by norepinephrine results from decreased NOS-2 promoter activity. J Neurochem 70:1484-1496.

Feinstein DL, Heneka MT, Gavrilyuk V, Dello Russo C, Weinberg G, Galea E (2001) Noradrenergic regulation of inflammatory gene expression in brain. Neurochem Int, in press.

Foote SL, Bloom FE, Aston-Jones G (1983) Nucleus locus ceruleus: new evidence of anatomical and physiological specificity. Physiol Rev 63:844-914.

Forno LS (1992) Neuropathologic features of Parkinson's, Huntington's, and Alzheimer's diseases. Ann NY Acad Sci 648:6-16.

Freedman R, Foote SL, Bloom FE (1975) Histochemical characterization of a neocortical projection of the nucleus locus coeruleus in the squirrel monkey. J Comp Neurol 164:209-231.

Fritschy JM, Grzanna R (1991) Experimentally-induced neuron loss in the locus coeruleus of adult rats. Exp Neurol 111:123-127.

Frohman EM, Vayuvegula B, van den NS, Gupta S (1988) Norepinephrine inhibits gamma-interferon-induced MHC class II (Ia) antigen expression on cultured brain astrocytes. J Neuroimmunol 17:89-101.

Galea E, Feinstein DL (1999) Regulation of the expression of the inflammatory nitric oxide synthase (NOS2) by cyclic AMP. FASEB J 13:2125-2137.

German DC, Manaye KF, White III CL, Woodward DJ, McIntire DD, Smith WK, Kalaria RN, Mann DM (1992) Disease-specific patterns of locus coeruleus cell loss. Ann Neurol 32:667-676.

Harro J, Pahkla R, Modiri A-R, Harro M, Kask A, Oreland L (1999) Dose-dependent effects of noradrenergic denervation by DSP-4 treatment on forced swimming and beta-adrenoceptor binding in the rat. J Neural Transm 106:619-629.

Heneka MT, Feinstein DL, Galea E, Gleichmann M, Wullner U, Klockgether T (1999a) Peroxisome proliferator-activated receptor gamma agonists protect cerebellar granule cells from cytokine-induced apoptotic cell death by inhibition of inducible nitric oxide synthase. J Neuroimmunol 100:156-168.

Heneka MT, Schmidlin A, Wiesinger H (1999b) Induction of argininosuccinate synthetase in rat brain glial cells after striatal microinjection of immunostimulants. J Cereb Blood Flow Metab 19:898-907.

Heneka MT, Klockgether T, Feinstein DL (2000) Peroxisome proliferator-activated receptor- $\gamma$ ligands reduce neuronal inducible nitric oxide synthase expression and cell death in vivo. J Neurosci 20:6862-6867.

Heneka MT, Wiesinger H, Dumitrescu-Ozimek L, Riederer P, Feinstein DL, Klockgether T (2001) Neuronal and glial coexpression of argininosuccinate synthetase and inducible nitric oxide synthase in Alzheimer disease. J Neuropathol Exp Neurol 60:906-916.

Hu J, Van Eldik LJ (1999) Glial-derived proteins activate cultured astrocytes and enhance beta amyloid-induced glial activation. Brain Res 842:46-54.

Hu XX, Goldmuntz EA, Brosnan CF (1991) The effect of norepinephrine on endotoxin-mediated macrophage activation. J Neuroimmunol 31:35-42.

Iversen LL, Rossor MN, Reynolds GP, Hills R, Roth M, Mountjoy CQ, Foote SL, Morrison JH, Bloom FE (1983) Loss of pigmented dopamine-beta-hydroxylase positive cells from locus coeruleus in senile dementia of Alzheimer's type. Neurosci Lett 39:95-100.

Kalaria RN, Stockmeier CA, Harik SI (1989a) Brain microvessels are innervated by locus ceruleus noradrenergic neurons. Neurosci Lett 97:203-208.

Kalaria RN, Andorn AC, Tabaton M, Whitehouse PJ, Harik SI, Unnerstall JR (1989b) Adrenergic receptors in aging and Alzheimer's disease: increased beta 2-receptors in prefrontal cortex and hippocampus. J Neurochem 53:1772-1781.

Lee SC, Collins M, Vanguri P, Shin ML (1992) Glutamate differentially inhibits the expression of class II MHC antigens on astrocytes and microglia. J Immunol 148:3391-3397.

Lee SC, Zhao ML, Hirano A, Dickson DW (1999) Inducible nitric oxide synthase immunoreactivity in the Alzheimer disease hippocampus: 
association with Hirano bodies, neurofibrillary tangles, and senile plaques. J Neuropathol Exp Neurol 58:1163-1169.

Lee SJ, Drabik K, Van Wagoner NJ, Lee S, Choi C, Dong Y, Benveniste EN (2000) ICAM-1-induced expression of proinflammatory cytokines in astrocytes: involvement of extracellular signal-regulated kinase and p38 mitogen-activated protein kinase pathways. J Immunol 165:4658-4666.

Levine ES, Litto WJ, Jacobs BL (1990) Activity of cat locus coeruleus noradrenergic neurons during the defense reaction. Brain Res 531:189-195.

Licinio J, Prolo P, McCann SM, Wong ML (1999) Brain iNOS: current understanding and clinical implications. Mol Med Today 5:225-232.

Loughlin AJ, Woodroofe MN, Cuzner ML (1993) Modulation of interferon-gamma-induced major histocompatibility complex class II and $\mathrm{Fc}$ receptor expression on isolated microglia by transforming growth factor-beta 1, interleukin-4, noradrenaline and glucocorticoids. Immunology 79:125-130.

Mann DM, Yates PO, Hawkes J (1982) The noradrenergic system in Alzheimer and multi-infarct dementias. J Neurol Neurosurg Psychiatry 45:113-119.

Mann DM, Yates PO, Hawkes J (1983) The pathology of the human locus ceruleus. Clin Neuropathol 2:1-7.

Marcyniuk B, Mann DM, Yates PO (1986) Loss of nerve cells from locus coeruleus in Alzheimer's disease is topographically arranged. Neurosci Lett 64:247-252.

Mason ST, Iversen SD (1975) Learning in the absence of forebrain noradrenaline. Nature 258:422-424.

Mavridis M, Degryse AD, Lategan AJ, Marien MR, Colpaert FC (1991) Effects of locus coeruleus lesions on parkinsonian signs, striatal dopamine and substantia nigra cell loss after 1-methyl-4-phenyl-1,2,3,6tetrahydropyridine in monkeys: a possible role for the locus coeruleus in the progression of Parkinson's disease. Neuroscience 41:507-523.

Mehlhorn G, Hollborn M, Schliebs R (2000) Induction of cytokines in glial cells surrounding cortical beta-amyloid plaques in transgenic Tg2576 mice with Alzheimer pathology. Int J Dev Neurosci 18:423-431.

Mrak RE, Sheng JG, Griffin WS (1995) Glial cytokines in Alzheimer's disease: review and pathogenic implications. Hum Pathol 26:816-823.

Nishino K, Lin CS, Morse JK, Davis JN (1991) DSP4 treatment worsens hippocampal pyramidal cell damage after transient ischemia. Neuroscience 43:361-367.
Paspalas CD, Papadopoulos GC (1998) Ultrastructural evidence for combined action of noradrenaline and vasoactive intestinal polypeptide upon neurons, astrocytes, and blood vessels of the rat cerebral cortex. Brain Res Bull 45:247-259.

Paxinos G, Watson C, Pennisi M, Topple A (1985) Bregma, lambda and the interaural midpoint in stereotaxic surgery with rats of different sex, strain and weight. J Neurosci Methods 13:139-143.

Scheibel AB, Duong TH, Tomiyasu U (1987) Denervation microangiopathy in senile dementia, Alzheimer type. Alzheimer Dis Assoc Disord 1:19-37.

Seguela P, Watkins KC, Geffard M, Descarries L (1990) Noradrenaline axon terminals in adult rat neocortex: an immunocytochemical analysis in serial thin sections. Neuroscience 35:249-264.

Sheng JG, Jones RA, Zhou XQ, McGinness JM, Van Eldik LJ, Mrak RE, Griffin WS (2001) Interleukin-1 promotion of MAPK-p38 overexpression in experimental animals and in Alzheimer's disease: potential significance for tau protein phosphorylation. Neurochem Int 39:341-348.

Sigurdsson EM, Scholtzova H, Mehta PD, Frangione B, Wisniewski T (2001) Immunization with a nontoxic/nonfibrillar amyloid-beta homologous peptide reduces Alzheimer's disease-associated pathology in transgenic mice. Am J Pathol 159:439-447.

Stewart WF, Kawas C, Corrada M, Metter EJ (1997) Risk of Alzheimer's disease and duration of NSAID use. Neurology 48:626-632.

Vodovotz Y, Lucia MS, Flanders KC, Chesler L, Xie QW, Smith TW, Weidner J, Mumford R, Webber R, Nathan C, Roberts AB, Lippa CF, Sporn MB (1996) Inducible nitric oxide synthase in tangle-bearing neurons of patients with Alzheimer's disease. J Exp Med 184:1425-1433.

Weldon DT, Rogers SD, Ghilardi JR, Finke MP, Cleary JP, O'Hare E, Esler WP, Maggio JE, Mantyh PW (1998) Fibrillar $\beta$-amyloid induces microglial phagocytosis, expression of inducible nitric oxide synthase, and loss of a select population of neurons in the rat CNS in vivo. J Neurosci 18:2161-2173.

Wilcock GK, Esiri MM, Bowen DM, Hughes AO (1988) The differential involvement of subcortical nuclei in senile dementia of Alzheimer's type. J Neurol Neurosurg Psychiatry 51:842-849.

Willis SA, Nisen PD (1995) Inhibition of lipopolysaccharide-induced IL-1 beta transcription by cyclic adenosine monophosphate in human astrocytic cells. J Immunol 154:1399-1406. 